\title{
Analysis of drug compatibility in $Y$ in intravenous therapy: preparation of a preventive tool for a university hospital in Petrolina - PE
}

\author{
Karina Duarte MORAES ${ }^{1}$, Izabella Virgínio GOMES ${ }^{2}$, Odara Pacheco LIMA ${ }^{1}$, Raissa Lima REIS ${ }^{1}$, Marcilene Nunes SOUZA², Natalia Dias FREIRE ${ }^{1}$, \\ Josilenne Ferreira BARROS ${ }^{1}$, Felipe Santana MEDEIROS ${ }^{2}$, Deuzilane Muniz NUNES ${ }^{3}$
}

${ }^{1}$ Programa de Residência Multiprofissional de Intensivismo da Universidade Federal do Vale do São Francisco - Pernambuco, ${ }^{2} \mathrm{Hospital}$ Universitário da Universidade Federal do Vale do São Francisco - Pernambuco, ${ }^{3}$ Universidade Federal do Vale do São Francisco - Pernambuco

Corresponding Author: Moraes KD, karinashayene@gmail.com

Submitted: 27-08-2020 Resubmitted: 09-12-2020 Accepted: 10-02-2021

Peer review: blind reviewers

\begin{abstract}
Objectives: To elaborate a tool for the analysis of the compatibility of intravenous medications in order to assist in the conduct and routines of the assistance teams of the Federal University of the São Francisco's Valley (HU-Univasf) Methods: Injectable drugs were initially selected, which belong to the HU-Univasf standardization list. Information on the $\mathrm{pH}$ of medications, compatibilities and incompatibilities were extracted from the databases: Lexi-comp ${ }^{\circledR}$ Inc, Micromedex IV Compatibility, Internet website Stabilis and King Guide to Parenteral Admixtures ${ }^{\circledR}$. This paper was carried out in two stages: (1) Creation of a tool to analyze the compatibility of injectable medications used in the hospital in a guide format; (2) Elaboration of the cross table for quick consultation of the compatibility of the most prevalent medications in the Intensive and Semi-Intensive Care Unit (UCISIN) in the parenteral dosage form for intravenous (IV) administration. Results: The Guide for analysis of Y compatibility in intravenous drug administration for a University Hospital in Petrolina-Pe, was published with ISBN (International Standard Book Number): 978-85-92656-19-5 and is available on the HU-Univasf institutional website for free access. This material served as basis for the construction of the drug compatibility chart that contains the 50 most distributed items from the pharmacy to the UCISIN. From this table, 1,225 pairs of drugs were obtained, of which $36 \%(\mathrm{~N}=444)$ corresponded to compatible pairs and $20 \%$ $(\mathrm{N}=241)$ to incompatible pairs. It should be noted that a higher value of pairs was observed with the undefined compatibility, $44 \%(N=540)$, that is, without data in the literature consulted Conclusions: It was possible to prepare the Guide for Analysis of Y Compatibility in Intravenous Medication Administration and the HU-Univasf Y-Drug Incompatibility Cross Table Graph, already available for the entire team. Therefore, it is expected that these instruments facilitate the access of the multidisciplinary team to reliable information, expanding the role of the pharmacist in the care of critical patients, improving patient safety in the use of intravenous medications in the hospital.
\end{abstract}

Keywords: drug incompatibility; critical care; administration; intravenous.

\section{Análise da compatibilidade medicamentosa em Y na terapia intravenosa: elaboração de ferramenta preventiva para um hospital universitário de Petrolina- PE}

\begin{abstract}
Resumo
Objetivos: Elaborar instrumento para a análise da compatibilidade de medicamentos intravenosos, com o intuito de auxiliar nas condutas e rotinas das equipes assistenciais do Hospital Universitário da Universidade Federal do Vale do São Francisco (HUUnivasf). Métodos: Foram selecionados inicialmente os medicamentos injetáveis, que pertencem a lista de padronização do HUUnivasf. As informações sobre o pH dos medicamentos, compatibilidades e incompatibilidades, foram extraídas das bases de dados: Lexi-comp ${ }^{\circledR}$ Inc, Micromedex IV Compatibility, Internet website Stabilis e King Guide to Parenteral Admixtures ${ }^{\circ}$. Este trabalho foi realizado em duas etapas: (1) Criação de uma ferramenta para a análise da compatibilidade de medicamentos injetáveis utilizados no hospital em formato de guia; (2) Elaboração de tabela cruzada para consulta rápida das compatibilidades dos medicamentos mais prevalentes da Unidade de Cuidados Intensivos e Semi-Intensivos (UCISIN), na forma farmacêutica parenteral para administração intravenosa (IV). Resultados: O Guia para análise da compatibilidade em Y na administração intravenosa de medicamentos para um Hospital Universitário de Petrolina-Pe, foi publicado com ISBN (International Standard Book Number): 978-85-92656-19-5 e está disponível no site institucional do HU-Univasf para acesso livre. O referido material serviu de base para a construção da tabela de compatibilidade de medicamentos que contém os 50 itens mais distribuídos da farmácia para a UCISIN. A partir dessa tabela,
\end{abstract}


foram obtidos 1.225 pares de medicamentos, dos quais $36 \%(\mathrm{~N}=444)$ corresponderam às duplas compatíveis e $20 \%(\mathrm{~N}=241)$ às duplas incompatíveis. Destaca-se que foi observado um valor maior de duplas com a compatibilidade indefinida $44 \%(\mathrm{~N}=540$ ), ou seja, sem dados nas literaturas consultadas. Conclusões: Foi possível elaborar o Guia para Análise da Compatibilidade em Y na Administração Intravenosa de Medicamentos e o Tabela cruzada de Incompatibilidade de Medicamentos Administrados em Y do HU-Univasf, já disponíveis para toda a equipe. Logo, é esperado que a elaboração desses instrumentos facilite o acesso da equipe multiprofissional a informações de qualidade e amplie o papel do farmacêutico no cuidado ao paciente crítico, melhorando a segurança do paciente no uso de medicamentos intravenosos do hospital.

Palavras-chave: incompatibilidade de medicamentos; cuidados críticos; administração intravenosa.

\section{Introduction}

Intravenous drug administration is frequently used in the health care routine of hospital units. It is an essential route for patients who require quick action of the drug, as well as for those in which oral therapy is precluded. However, choosing this route implies potential risks, which can lead to harms., ${ }^{1,2}$

Drug incompatibility, also known as pharmaceutical interaction, is a risk associated with intravenous drug administration. It consists in an undesirable physical and/ or chemical reaction, caused by the combination of two or more medications in the same solution. The product of this reaction may or may not affect therapy efficacy. ${ }^{1}$ These incompatibilities can be classified as follows: physical, when there is the formation of precipitates, change of color and/ or consistency; and chemical, characterized by molecular changes. As a result of these changes, there is formation of inactive, toxic substances, decrease of stability, change of organoleptic characteristics, catheter occlusion, embolism, or inflammatory reactions. ${ }^{2,3}$ When two drugs are simultaneously infused, through an infusion $Y$ connector, they should have compatibility guaranteed. ${ }^{3}$

These pharmaceutical interactions are commonly found in Intensive Care Units (ICUs). The patients hospitalized in ICUs generally need a large number of medications, mostly through a continuous parenteral route and, sometimes, administered concomitantly. All these factors, added to the presence of intravenous infusion devices with reduced routes, contribute to possible incompatibilities during the administration process. Differently from the drug interactions that occur in the organism, incompatibilities take place before the medication enters into contact with the body. 2,3,4,5

A large percentage of the drug incompatibilities present reduced clinical significance. Others, however, represent a considerable risk for the patient. The severity of these instances will depend on the intrinsic factors of the medication, as well as on the general condition of the patient. ${ }^{6}$ In this way, it is important to assist the care teams with quick and reliable information, which may help in the prevention of incompatibilities. This information can ensure the effectiveness of the drug therapy, contributing to therapeutic success and favoring patient safety.

In this regard, this study aimed at elaborating an instrument for analysis of $Y$ compatibility in the intravenous (IV) administration of medications for use in the intensive care unit of a university hospital in Petrolina, Pernambuco, Brazil.

\section{Methods}

The study was conducted from July to September 2019 in the Hospital Pharmacy Sector (HPS) and in the Intensive Care Unit of the University Hospital of the Federal university of the São Francisco's Valley (Hospital Universitário da Universidade Federal do Vale do São Francisco, HU-Univasf), referred to as an Intensive and Semi-Intensive Care Unit (Unidade de Cuidados Intensivos e Semi-Intensivos, UCISIN). It was developed in two stages: (1) Preparation of a tool for the analysis of $Y$ compatibility in the intravenous administration of medications for a university hospital in Petrolina-PE, in guide format; (2) Identification of the most distributed medications to the UCISIN of the HU-Univasf for subsequent preparation of the cross table for quick consultation of compatibility of medications administrated intravenously.

To elaborate the compatibility guide, initially, a list of the medications administered intravenously used in the HU-Univasf was defined. The institution's list of standardized medications was used, which includes 311 items to meet the service requirements. Only the injectable medications that can be administered through the IV route were included, based on the administration route recommended in the manufacturer's insert of each medication. The presence of duplicate drugs (containing the same drug in different concentrations) was also assessed. Therefore, considering that the studies on drug incompatibilities are related to the contact time between the substances ${ }^{2}$ and not to their amount (dose and concentration), duplicate medications were excluded. To structure the guide, the standard model of the materials produced by the Clinical Pharmacy (CP) of the HPS at the HU-Univasf was used. The guide presented the name of each medication, with information regarding the $\mathrm{pH}$ of their active ingredients and the medications that are compatible and incompatible with them.

A study was conducted to identify the medications that were most frequently distributed to the UCISIN in the period from July 2018 to June 2019. Retrospective data was collected from the reports of the medications requested by the unit each month, available in the pharmacy, without any patient information. After quantification, the 50 most prevalent medicines were classified to elaborate the instrument, according to what is exemplified in the material prepared by Maison et al. (2019) ${ }^{3}$.

In the preparation of the cross table with the 50 most frequently dispensed medications, three researchers (pharmacists) collaborated, one in data organization and two in the review. In the elaboration, the pairs of drugs and their compatibility in $Y$ infusion were considered. Drugs were organized alphabetically, followed by the drugs' pH (when available), correlated to the other drugs, and evaluated the compatibility data. The information between the pairs of drugs was signalized by standardized colors and letters, as follows: 
- Compatible: the letter " $C$ " was used, highlighted inside a green box;

- Incompatible: the letter "I" was used, highlighted inside a red box;

- Unknown (no information in the literature): only a gray box was used;

- Drugs with acid pH: yellow box;

- Drugs with basic pH: blue box;

- Drugs with neutral pH: white box.

When conflicting data were observed in the literature, the pair was considered as incompatible if at least one of the sources reported incompatibility ${ }^{3}$.

The diverse information on $\mathrm{pH}$, compatibilities, and incompatibilities for each drug were consulted and extracted from the following databases:

1. Lexi-comp ${ }^{\circledast}$ Inc. and American Pharmaceutical Association. Trissel's IV Compatibility. Lexi-Comp ${ }^{\circledR}$ Inc, 20198;

2. Micromedex IV Compatibility ${ }^{9}$;

3. Internet website Stabilis. Available in www.stabilis.org ${ }^{10}$;

4. King Guide to Parenteral Admixtures. Available in https:// kingguide.com ${ }^{11}$.

All the medications were checked in each of the databases, following the aforementioned sequence. Eventual incompatibilities of the medications with medical materials, solutions and damage due to exposure to light were not described.

Conduction of the project was authorized by the Research Management and Technological Innovation Sector of the HUUnivasf, by issuance of the corresponding Consent Letter (Authentication: sge2957k587-390). No approval in research ethics committees was necessary, for this being a paper in which the data used were only from the hospital pharmacy management area, with the names of the medications and their amounts distributed in the hospital and by clinical sector, without any direct or indirect involvement of research participants' data.

\section{Results}

A guide for analyzing $Y$ compatibility in intravenous (IV) administration of medication with all IV medications standardized in the HU-Univasf was prepared, and a compatibility cross table with the 50 IV medications administered in $\mathrm{Y}$ most frequently distributed to the UCISIN of the HU-Univasf.

The guide for the analysis of $Y$ compatibility in intravenous drug administration for a University Hospital of Petrolina-PE was published with ISBN (International Standard Book Number): 97885-92656-19-5 and is available on the HU-Univasf institutional site for free access12. This guide presents information of $Y$ compatibility of 111 medications administered through IV in the HU-Unisaf. Based on the hospital's list of standardized medications, with a total of 311 drugs, the 120 (38.6\%) injectable medications administered intravenously were selected for inclusion in the guide. Of these, nine duplicate drugs were observed. Consequently, the final version included 111 available injectable medications administered intravenously.

The data obtained in identifying the injectable medications for IV administration, distributed to the UCISIN, were organized month by month, with their respective amounts, presented in Table 1, from July 2018 to June 2019. A monthly mean of $5.728 \pm 925$ injectable medications was observed, with April 2019 standing out, a month in which there was a greater distribution frequency of these medications to the UCISIN. Of the 111 injectable medications for IV administration, $17.1 \%(N=19)$ were not distributed to the UCISN in this period analyzed, as shown in Table 2.

Table 1. Number of injectable medications for intravenous administration distributed from the Hospital Pharmacy Sector (HPS) to the Intensive and Semi-Intensive Care Unit of the University Hospital of the Federal University of the São Francisco's Valley, in Petrolina, Pernambuco, during the period from June 2018 to July 2019.

\begin{tabular}{ll}
\hline Month/Year & Number of medications \\
\hline July 2018 & 5,599 \\
August 2018 & 4,414 \\
September 2018 & 5,157 \\
October 2018 & 5,367 \\
November 2018 & 5,180 \\
December 2018 & 6,053 \\
January 2018 & 4,958 \\
February 2019 & 5,395 \\
March 2019 & 6,784 \\
April 2019 & 7,924 \\
May 2019 & 6,634 \\
June 2019 & 5,269 \\
TOTAL & 68,734 \\
\hline
\end{tabular}

Table 2. List of the injectable medications for intravenous administration not distributed from the Hospital Pharmacy Sector (HPS) to the Intensive and Semi-Intensive Care Unit of the University Hospital of the Federal University of the São Francisco's Valley, in Petrolina, Pernambuco, during the period from June 2018 to July 2019.

\begin{tabular}{ll}
\hline Medications & \\
\hline Acetylcysteine & Ethanolamine \\
Alteplase & Etilephrine \\
Aminophylline & Mesna \\
Cyclophosphamide & Nalbuphine \\
Radiological contrast based on iodized poppy seed oil & Pentoxifylline \\
Non-ionic radiological contrast & Pethidine \\
Dantrolene & Remiphentanil \\
Droperidol & Terbutaline \\
\hline
\end{tabular}

The first 50 medications administered through the IV route most distributed to the UCISIN were selected, organized, and separated by therapeutic group, according to the ATCC (Anatomical Therapeutic Chemical Code) classification adopted by the WHO, and to the general distribution frequency to the sector concerning 
all the IV medications of the hospital (Table 3) 13. The medicines that were most frequently distributed to this unit belonged to the group of the anti-infective agents for systemic use (28.2\%), followed by the groups acting on the nervous system (22.8\%) and the digestive tract and metabolism (21.1\%).

Table 3. Classification according to the Anatomical Therapeutic Chemical Code (ATCC) and distribution frequency of the 50 injectable medications for intravenous administration that were most frequently distributed from the Hospital Pharmacy Sector (HPS) to the Intensive and Semi-Intensive Care Unit of the University Hospital of the Federal University of the São Francisco's Valley, in Petrolina, Pernambuco, during the period from June 2018 to July 2019.

\begin{tabular}{|c|c|c|}
\hline Drug Groups & ATC & $\begin{array}{l}\text { Distribution } \\
\text { Frequency } \\
(\%)\end{array}$ \\
\hline Antiinfectives For Systemic Use & J & 28,2 \\
\hline Antibacterials for systemic use & J01 & 27,9 \\
\hline Antimycotics for systemic use & $\mathrm{J} 02$ & 0,1 \\
\hline Antivirals for systemic use & $\mathrm{J} 05$ & 0,2 \\
\hline Nervous System & $\mathrm{N}$ & 22,8 \\
\hline Anesthetics & N01 & 2,5 \\
\hline Analgasics & N02 & 13,3 \\
\hline Antiepileptics & N03 & 4,2 \\
\hline Psycholeptics & N05 & 2,8 \\
\hline Alimentary Tract And Metabolism & $A$ & 21,1 \\
\hline Drugs for acid related disorders & A02 & 12,6 \\
\hline Drugs for functional gastrointestinal disorders & $\mathrm{A} 03$ & 7,0 \\
\hline Vitamins & A11 & 0,7 \\
\hline Antiemetics and antinauseants & $\mathrm{A} 04$ & 0,8 \\
\hline $\begin{array}{l}\text { Systemic Hormonal Preparations, Excl. Sex } \\
\text { Hormones And Insulins }\end{array}$ & $\mathrm{H}$ & 2,8 \\
\hline Corticosteroids for systemic use & $\mathrm{HO2}$ & 2,8 \\
\hline Blood And Blood Forming Organs & $\mathrm{B}$ & 2,4 \\
\hline Antihemorrhagics & $\mathrm{B} 02$ & 0,3 \\
\hline Blood substitutes and perfusion solutions & B05 & 2,1 \\
\hline Cardiovascular System & $\mathrm{C}$ & 2,4 \\
\hline Cardiac therapy & $\mathrm{CO1}$ & 1,9 \\
\hline Diurétics & $\mathrm{CO3}$ & 0,5 \\
\hline Musculo-Skeletal System & M & 0,5 \\
\hline Muscle relaxants & M03 & 0,5 \\
\hline $\begin{array}{l}\text { Total units of the } 50 \text { most widely distributed } \\
\text { intravenous drugs for the UCISIN }\end{array}$ & 55.128 & 80,2 \\
\hline $\begin{array}{l}\text { Total intravenous medicinal products } \\
\text { distributed to the UCISIN }\end{array}$ & 68.734 & 100 \\
\hline
\end{tabular}

The cross table of $Y$ compatibility (Figure 1) with the 50 most frequently dispensed medications was prepared, having 1,225 pairs of medications, of which $36.2 \%(\mathrm{~N}=444)$ corresponded to the compatible pairs and $19.7 \%(\mathrm{~N}=241)$, to the incompatible pairs. It is noteworthy that a higher value of pairs with undefined compatibility was observed, $44.1 \%(N=540)$, that is, with no information in the databases consulted. In these cases where there was no information that ensured compatibility, the indication was to consider them as incompatible in the clinical practice, for greater patient safety. Some medications, such as: scopolamine, trace elements, multivitamins, bromopride and dipyrone, did not present information related to compatibility in the databases consulted. Phenytoin and diazepam, on their turn, were the medications most associated with pairs of incompatibilities (Figure 1).

\section{Discussion}

Intravenous drug administration is frequently used in the hospital setting. The number of medications administered concomitantly and the use frequency of this route are directly linked to the patient's onset of harm. ${ }^{4}$ More than one-third of medications used in the hospital were availed in presentations for intravenous use, in our study. Therefore, the preparation of the Guide for the Analysis of Y Compatibility in Intravenous Drug Administration and the Table of Incompatibility of Medications Administered in $Y$ of the HU-Univasaf can be useful for the clinical practice, in order to ensure more safety to the patient in the use of IV medications.

The analysis conducted is relevant, as it gathers diverse information about medication compatibility coming from different databases in a table that is easy to see and to understand, based on the methodological approach proposed by Maison, et al. (2019). Cross tables expose the compatibility of administration in $Y$ for all pairs of medications, and describe the drugs' $\mathrm{pH}$, those with extreme $\mathrm{pH}$ being highlighted with colors. This strategy is important to promote quick information about the incompatibilities between different IV medications and to prevent adverse events in health care $^{3}$.

The literature points out various cross tables of medications with data on incompatibilities. ${ }^{14,15,16,17,18}$ It is suggested that theses tables are produced targeting a specific clinical unit, as was the case in this paper for the UCISIN of the HU-Unisaf. In addition, these instruments have been considered quite useful and easily understandable by nurses. ${ }^{18}$ This study, however, did not have the objective of assessing the impact of using the table in the clinics, which should be done in the future.

Intravenous therapy is considered complex and involves several stages, such as: identification of the Peripheral Venous Access (PVA), validity of the PVA, identification of the venous infusion equipment, validity of the equipment for venous infusion, identification of the serum vials, verification of the medication to be administered against the prescription and infusion time, among others. ${ }^{19}$ It is therefore subjected to many errors. Incompatibilities represent nearly $14 \%$ of the medication errors in ICUs. However, these errors are considered avoidable, that is, mechanisms and actions can be implemented to prevent possible harms to the patients. ${ }^{2}$

Besides, due to the multiple pathologies of the critical patient, treatment becomes broader, demanding a variety of procedures and care, such as infusions of solutions, blood transfusions, blood products and injectable medications, which are more frequently involved in medication errors. Therefore, it is necessary to know the profile of the intensive care unit, as well as the most used medications and their particularities, in order to develop action plans and prevent harms. ${ }^{20,21}$

In this with, by elaborating this paper's instruments, it was possible to describe the intravenous medications that were most frequently distributed to the ICU sector of the HU-Univasf. In this sense, the injectable medications that were most frequently distributed to the UCISIN were compared to the institution's general list of standardized medications. It was verified that almost one fifth of the standardized intravenous medications in the hospital were not distributed to this sector during the data collection period. Many of these medications, among them dantrolene, droperidol, ethanolamine, nalbuphine, pentoxifylline, remifentanil, alteplase, neostigmine and pethidine, are drugs commonly used in surgical and emergency rooms. ${ }^{22}$ 
Figure 1. Cross table of Compatibility of intravenous medications administered in Y in the UCISIN of the University Hospital of the Federal University of the São Francisco's Valley in Petrolina, Pernambuco.

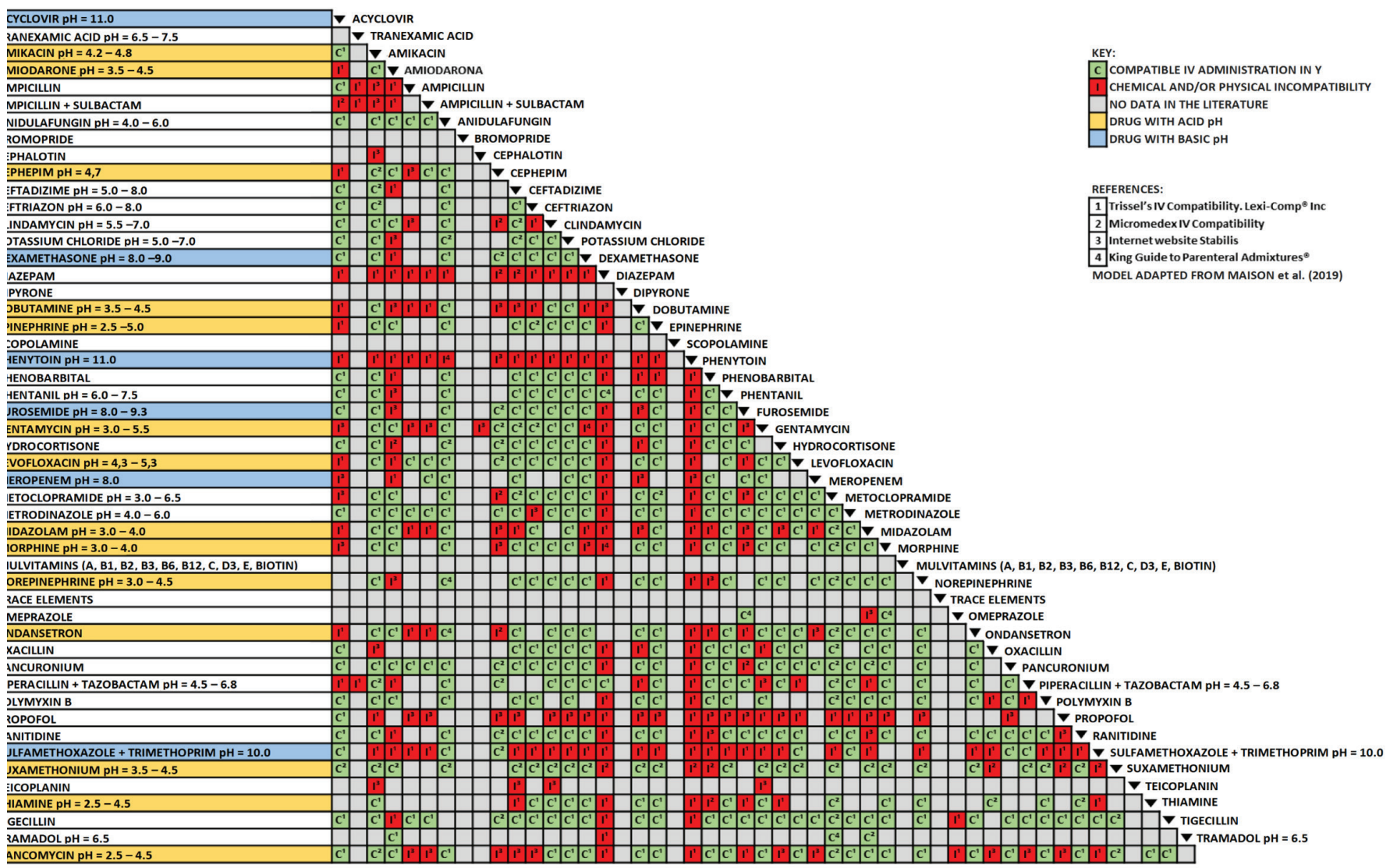

For the clinical sector analyzed in this study, the UCISIN of the HUUnivasf, which is an Intensive Care Unit, the monthly mean of injectable medications distributed was close to six thousand units. In a general manner, the use of intravenous medications is of great importance for ICUs' clinical practice. Their use is frequent and indispensable in patients who need quick start of the pharmacological effect or when obstacles are precluding oral administration. It is also worth noting that some medications are not available in solid pharmaceutical presentations for the oral route, parenteral use being indispensable. However, when chosen, intravenous administration has inherent risks, including drug incompatibilities. ${ }^{23}$

These incompatibilities occur due to concomitant drug administration, which is often the result of the high volume of drugs exceeding the number of available venous lines. Chemical incompatibility is characterized by molecular changes and is considered significant when there is more than $10 \%$ degradation in at least one component of the solution, being a slow, irreversible and invisible reaction. On its turn, physical incompatibility includes visible and quick reactions, such as precipitation, turbidity, change of color and subvisible reactions, such as: change of $\mathrm{pH}$, release of gas, emergence of microparticles and decrease in drug concentration. In this context, most of the incompatibilities are not visible and lead to a reduction in the concentration of the drug or to its toxicity. ${ }^{2,6,24}$

These reactions are scarcely described in the hospital setting, generally due to the professional's lack of technical expertise in perceiving them. Furthermore, patients hospitalized in ICUs are more prone to incompatibilities due to the aforementioned reasons. ${ }^{2}$ It is important to observe the manifestation of these reactions and the risk of repercussions in changes of the efficiency of the medications and/or problems related to patient safety. ${ }^{24}$

The literature shows that the formation of precipitates due simultaneous drug administration can affect the bloodstream, compromising tissue perfusion and the function of vital organs, in addition to generating fatal cardiopulmonary complications. ${ }^{24}$ The consequences of these incompatibilities range from a simple catheter obstruction to the patient's death. In this sense, the pharmacists must devise measures to help in the practice of the multi-professional team. They need to act, mainly, in the promotion of information about the risks of concomitant drug administration. However, there is scarcity of studies in this area, which contributed to the limitations of the health services for safe drug administration. ${ }^{4}$

Among the 50 medications most frequently distributed to the ICU of the hospital under study, considering the formation of 1,225 pairs, slightly more than one third of those pairs consisted of compatible medications, whereas almost one fourth were incompatible pairs. A study conducted by Gaetani, et al. (2017) showed that $62 \%$ of the drug administration procedures in an ICU were compatible; whereas another study conducted by Marsílio, Silva and Bueno (2016) identified that $15 \%$ of the medication pairs were incompatible. As observed, the data mentioned refer that the frequency of compatible medications is higher than that of incompatible drugs, which corroborates this study. However, it is worth noting that there was no numerical approximation between the rates described in the literature $e^{2,7}$ and those obtained in this paper. 
In parallel to these data, undefined compatibilities accounted for more than $40 \%$ of the pairs of medications, and this is due to the lack of studies on the topic and of clinically relevant data, corroborating other authors that also showed a high rate of untested compatibilities. ${ }^{2,3,4,7}$ The main example among these medications is dipyrone, as there is little information in the scientific literature. Such fact is justified because the drug is not available in many countries, including the United States, which is responsible for a large part of the databases and scientific publications in this area. Therefore, there is disinterest in conducting studies with medications not available in this country. ${ }^{4}$

Regarding the combinations found, phenytoin and diazepam presented a higher number of incompatibilities among the medications. By observing the data available in the databases consulted, the incompatibilities are reported by the emergence of precipitates. ${ }^{9}$ Some studies showed that the incompatibilities most commonly found in ICUs were related to midazolam, cephepim and piperacillin associated with tazobactam. It was also reported that the presence of medications like diazepam, phenobarbital, phenytoin and metronidazole in the prescriptions is a risk factor for drug incompatibilities. ${ }^{4}$ All these data are present in the instruments elaborated in this study.

One of the important factors addressed was $\mathrm{pH}$. When combined acid and basic substances can lead to the emergence of chemical reactions, forming a precipitate (a salt). This can happen mainly in medications that present an extreme $\mathrm{pH}$, such as phenytoin ${ }^{3}$. In addition to that, a number of studies show that the infusion of solutions with a pH that is very different from that of the blood $(7.35-7.45)$ can cause damages to the vascular endothelium, and it is recommended that medications outside the $\mathrm{pH}$ range of 5.0 to 9.0 are administered in high flow veins. On the other hand, some drugs with a $\mathrm{pH}$ close to neutral, such as meropenem, can also produce toxic effects in the endothelial cells. ${ }^{20}$

These harms are reported in the literature, even in light of the scarcity of the studies in the area. A systematic review conducted by Benlabed, et al. (2019) showed that these incompatibilities, with formation of precipitates, can induce or worsen organic dysfunctions in hospitalized patients. Among the possible mechanisms of these lesions to the organs, we can mention the following: platelet activation, recruitment of granulocytes and blocking of microvessels, among others, which contribute to the formation of occlusive microthrombi, and may, more severely, lead to trauma or sepsis. ${ }^{6}$

It is reported that the first incompatibility case was described by the Food and Drug Administration (FDA) with ceftriaxone administered along with a substance containing calcium. After administration, a ceftriaxone-calcium complex was formed, presenting the form of a white precipitate, which caused cardiorespiratory arrest in seven newborns due to pulmonary embolism. ${ }^{8}$

In view of all the aforementioned aspects, it is known that most of the studies focus on the physical incompatibilities, evidencing their clinical implications. On the other hand, the chemical incompatibilities that may induce degradation of medications and/or formation of toxic substances are neglected. ${ }^{6}$ Therefore, implementing measures to prevent incompatibilities, such as the use informative instruments aiding this control, should be part of the health services' routine.

Based on the guide elaborated in this paper, it is possible to infer some measures that can be adopted to avoid possible harms in the patient related to the use of medications administered concomitantly, in the same access and through the IV route; among them, it is important to highlight the following: 1) Whenever it is possible to administer medications through a different access or at a different time; 2) Wash the infusion system used before and after each administration with a neutral solution, such as a $0.9 \%$ saline solution; 3) Using a multi-lumen device.

Numerous venous accesses can increase the risk of infections and thromboembolic complications. In view of the need for intensive care and the use of many medications through infusion, it is that incompatibilities occur. In this context, the health team must assess the risk-benefit ratio of the conducts. ${ }^{24}$ To avoid concomitant drug administrations that are potentially incompatible, it is necessary to plan the infusions to find the compatibility pairs. For this plan, much information needs to be analyzed, such as: availability of vascular access and its lumens, sparing a lumen for the administration of urgent fluids, the risks of administration of some medications through the central and peripheral routes, and/or knowledge about the compatibilities. This care requires time from the Nursing team, which is usually overloaded. Therefore, the presence of the clinical pharmacist in the ICU can help in these choices. ${ }^{7}$

In this way, the involvement of the pharmacists in pharmacotherapy brings huge benefits to the health services. They can collaborate with the multi-professional team and lead it to the best solution for the problems related to drug incompatibility. It is important that all professionals are aware of these problems and that the pharmacist is recognized in this role, making care more comprehensive and complete, considering the different knowledge areas.'

The instruments developed in this paper should facilitate the work of the pharmacist and the multi-professional team, improving critical patient safety in the use of IV medications. It is also expected that more hospital pharmacists will be made aware of the importance of developing guides and cross tables for analyzing $Y$ compatibility in the administration of IV drugs according to the institutional reality and the clinical sectors, especially for the units that assist critical patients.

However, more studies are necessary in order to understand the medication compatibilities that were not defined based on the literature consulted, encompassed almost half of the pairs investigated. It is also important to analyze the existing possible incompatibilities through pharmacotherapy monitoring to intervene and search solutions for the most severe incompatibilities found and, thus, contribute to patient safety. It is also necessary to assess the clinical impacts of using the instruments proposed in this study.

\section{Conclusion}

It was possible to develop two tools for quick analysis of $Y$ compatibility in intravenous (IV) administration of the medications used at the University Hospital of the Federal University of the São Francisco's Valley (HU-Univasf) in Petrolina, Pernambuco. Diverse information about medication incompatibilities from various databases was compiled in a guide and table that are easy to understand and offer quick access to safe information.

With the frequent administration of incompatible IV medications in critical patients, creating a compatibility cross table directed to an intensive care unit becomes crucial to promote patient safety. Therefore, it is expected that, with the use of the instruments elaborated, access of the multidisciplinary team to reliable information is enhanced, contributing to enhancing safety in the use of intravenous medications. In this context, it is also expected 
to expand the pharmacist's role in the care of critical patients in this hospital and raise awareness in more professionals to conduct studies like this in more hospital institutions.

\section{Funding sources}

The research did not receive funding for its conduction.

\section{Collaborators}

MKD collected the data and wrote the manuscript. NDM helped in structuring the project and conducted the critical review of the text. SMN and MFS helped in data collection. GIV, LOP, RRL, FND and BJF contributed substantially with suggestions that were incorporated, and with the critical review of the text. All the other authors approved the final version of the manuscript.

\section{Conflict of interest statement}

The authors declare that there are no conflicts of interest regarding this article.

\section{References}

5. Garcia JH. Incompatibilidade de medicamentos intravenosos e fatores de risco em pacientes críticos: coorte histórica. [Dissertação (Mestrado)]. Escola de Enfermagem da Universidade de São Paulo, São Paulo, 2015.

6. Marsilio NR, Silva D, Bueno D. Incompatibilidades medicamentosas em centro de tratamento intensivo adulto de um hospital universitário. Rev Bras Ter Intensiva. 2016; 28 (2): 147-153. DOI: 10.5935/0103-507X.20160029.

7. Maison O, Tardy C, Cabelgunne D, et al. Drug incompatibilities in intravenous therapy: evaluation and proposition of preventive tools in intensive care and hematology units. Eur J Clin Pharmacol. 2019;75 (2): 179-187. DOI: DOI: 10.1007/s00228-018-2602-6.

8. Leal KDB, Leopoldino RWD, Martins RR, et al. Potential intravenous drug incompatibilities in a pediatric unit. Einstein. 2016;14 (2): 185-189. DOI: 10.1590/S167945082016 AO3723.

9. Paes GO, Moreira SO, Moreira MB, et al. Incompatibilidade medicamentosa em terapia intensiva: revisão sobre as implicações para a prática de enfermagem. Rev. eletrônica enferm. 2017; 19: 1-13. DOI: 10.5216/ree.v19.38718.

10. Benlabed M, Perez M, Gaudy R, et al. Clinical implications of intravenous drug incompatibilities in critically ill patients. Anaesth Crit Care Pain Med. 2019; 38 (2): 173-180. DOI: 10.1016/j.accpm.2018.04.003.

11. Gaetani M, Frndova H, Seto W, et al. Concurrent intravenous drug administration to critically ill children: Evaluation of frequency and compatibility. J Crit Care. 2017; 41: 198-203. DOI: DOI: 10.1016/j.jcrc.2017.05.027.

12. Lexi-comp ${ }^{\circledR}$ Inc. and American Pharmaceutical Association. Trissel's IV Compatibility. Lexi-Comp ${ }^{\circledR}$ Inc, 2019. Available in: https://online.lexi.com/lco/action/login. Accessed: August-September 2019.
13. Micromedex IV, Compatibilidade,"Banco de dados online" 2019. Available in:<Aplicativo para Android>. Accessed: August-September 2019.

14. Isabelle DG, Mikael DD, Beatrice PD, et al. Internet website Stabilis. Available in: www.stabilis.org. Accessed on: August 2019.

15. King, J. Catania, P. King Guide to Parenteral Admixtures. 2019. Available in: https://kingguide.com. Accessed on: February 2019.

16. Moraes KSD, Lima OLP, Reis RL. Guia para análise da compatibilidade em Y na administração intravenosa de medicamentos do Hu-Univasf. 1ed. Petrolina- Pe, 2019.

17. Ministério da Saúde (Brasil). Código ATC. 2019. Available in: http://www.anvisa.gov.br/datavisa/Substancia/ATC.htm. Accessed: November 2019.

18. Cayo L. Compatibility of commonly used IV drugs. Pharm Pract News. 2011; 67-72.

19. Hôpitaux Universitaires de Genève. Compatibilités des médicaments injectables administrés en Y. Available in:https://pharmacie.hugge.ch/infomedic/utilismedic/HUG_CompatAdm_ DCl.pdf. Accessed 24 Oct 2017. Accessed: December 2020.

20. Kanji S, Lam J, Johanson C, et al. Systematic review of physical and chemical compatibility of commonly used medications administered by continuous infusion in intensive care units. Crit Care Med. 2010; 38: 1890-1898. DOI: 10.1097/ cCM.0b013e3181e8adcc

21. Trissel LA. Everything in a compatibility study is important. Am J Health Syst Pharm. 1996; 53: 2990. DOI: 10.1093/ ajhp/53.24.2990

22. Huddleston J, Hay L, Everett JÁ. Patient-specific compatibility tables for the pediatric intensive care unit. Am J Health Syst Pharm. 2000; 57: 2284-2285. DOI: 10.1093/ajhp/57.24.2284

23. MURASSAKI, Ana Claudia Yassuko, et al. Avaliação de cuidados na terapia intravenosa: desafio para a qualidade na enfermagem. Escola Anna Nery, 2013; 17 (1): 11-16. DOI: 10.1590/ S1414-81452013000100002.

24. Palau MM, Juan EP. Seguridad del paciente en la administración de antibióticos: evaluación del riesgo. Rev Calid Asist. 2017; 32 (3): 178-186. DOI: 10.1016/j.cali.2016.10.004.

25. Miranda TMM, Ferraresi AA. Compatibility: drugs and parenteral nutrition. Einstein (São Paulo). 2016; 14 (1): 52-55. DOI 10.1590/S1679-45082016A03440

26. Soares DB, Oliveira DMS, Faria JCM. Instituto para práticas seguras no uso de medicamentos (ISMP). Segurança no uso de medicamentos em cirurgia.: Available in https://www.ismp-brasil.org/site/wp-content/uploads/2018/05/boletim-seguranca-medicamentos-cirurgia.pdf. Accessed: November 2019.

27. Lima MG, Álvares J, Junior AAG, et al. Indicators related to the rational use of medicines and its associated factors. Rev. Saúde Pública. 2017; 51 (2): $23 . \quad$ DOI: 10.11606/S15188787.2017051007137

28. Leopoldino RW, Costa HT, Costa TX, et al. Potential drug incompatibilities in the neonatal intensive care unit: a network analysis approach. BMC Pharmacol Toxicol. 2018; 19 (1): 83. DOI: 10.1186/s40360-018-0265-7. 